\title{
FutureJournal
}

\section{Uso de Design Thinking como Experiência de Prototipação de Ideias no Ensino Superior}

\author{
Amilton Rodrigo de Quadros Martins \\ Doutorando em Educação pela Universidade de Passo Fundo (UPF), Brasil \\ amilton@imed.edu.br \\ Gláuber Guilherme Signori \\ Mestrando em Administração pela Faculdade Meridional (IMED), Brasil \\ glauber_signori@hotmail.com
}

Márcia Rodrigues dos Santos Capellari

Doutoranda em Administração pela Universidade Municipal de São Caetano do Sul (USCS), Brasil marcia@imed.edu.br

\section{Suellen Spinello Sotille}

Doutoranda em Administração pela Universidade Municipal de São Caetano do Sul (USCS), Brasil suellen.sotille@imed.edu.br

\section{Fahad Kalil}

Mestre em Computação pela Universidade Federal do Rio Grande do Sul (UFRGS), Brasil fahad.kalil@imed.edu.br

\section{RESUMO}

Neste artigo apresenta-se um caso de uso do Design Thinking em uma disciplina de curso de graduação. O Design Thinking, que visa proporcionar uma inovação na forma de pensar, é composto por um ciclo de etapas que compreendem inspiração, ideação e implementação. Atualmente o termo inovação tem-se mostrado em ascensão em conjunto com o grande número de startups e a intensa procura das empresas para adaptar-se às novas tecnologias e criar diferenciais competitivos no meio em que atuam. Como experimento, foi utilizado o Design Thinking na disciplina de Criatividade e Inovação, na graduação de Sistemas de Informação, sendo executados os passos de imersão, projeto, protótipo e validação, com o objetivo de gerar ideias de serviços inexistentes ou deficitários no campus da faculdade e que poderiam ser oferecidos por terceiros. Após a descrição das etapas do experimento, são apresentados alguns resultados qualitativos e quantitativos e previsões para trabalhos futuros.

PALAVRAS-CHAVE: Design thinking. Inovação. Startups. 


\section{FutureJournal}

\section{Use of Design Thinking as Ideas Prototyping Experience in Higher Education}

\section{ABSTRACT}

This article presents a case of using Design Thinking in a course of an undergraduate degree. The Design Thinking offers an innovation in thinking, consisting of a cycle of steps comprising inspiration, ideation and implementation. Assuming that it has currently shown on the rise the term innovation together with the large number of startups and the high demand of enterprises to adapt new technologies and create competitive advantages in the environment in which they operate. As experiment we used the Design Thinking in a course of Creativity and Innovation in Undergraduate of Information Systems, running the steps of immersion, design, prototyping and validation, in order to generate non-existent or deficit services ideas that might be offered by third parties in the campus of the college. After the description of the steps of the experiment, are presented some qualitative and quantitative results and future work.

KEY-WORDS: Design thinking. Innovation. Startups. 


\section{INTRODUÇÃO}

Segundo Brown (2010), as empresas na atualidade não estão habituadas a abordar novas ideias, pois acabam restringindo-as aos modelos de negócios já existentes pelo fato de que os modelos de negócios tradicionais são incrementais, previsíveis e fáceis de serem copiados, ao contrário de novas ideias que geram a incerteza.

Com a intenção de se diferenciarem e de se manterem competitivas, as empresas utilizam diversas estratégias, que em geral são tradicionais e já conhecidas. Contudo, neste artigo o objetivo é proporcionar uma nova perspectiva apresentando a metodologia Design Thinking.

Dessa forma, a inovação é considerada atualmente um fator estratégico das empresas, uma vez que os líderes olham para a inovação como a principal fonte de diferenciação e vantagem competitiva.

Verifica-se que:

Precisamos de uma abordagem à inovação que seja poderosa, eficaz e amplamente acessível, que possa ser integrada a todos os aspectos dos negócios e da sociedade e que indivíduos e equipes possam utilizar para gerar ideias inovadoras que sejam implementadas e que, portanto, façam a diferença. (Brown, 2010, p. 3).

Dessa forma, a inovação é considerada atualmente um fator estratégico das empresas, uma vez que os líderes olham para a inovação como a principal fonte de diferenciação e vantagem competitiva.

\section{REVISÃO DA LITERATURA}

\subsection{DESIGN THINKING E SUA PROPOSTA}

Um estudo de 2006 comprova que algumas empresas avaliam o design como uma das principais ferramentas para obter a inovação (Boston Consulting Group, 2006). Nesse sentido, considerando as informações acerca das características dessas empresas, Franzato (2011, p.52 ) aponta:

Os processos de inovação dirigida pelo design destacam-se dos processos de desenvolvimento de novos produtos tradicionais e vão em direção de 
uma reconsideração geral da atuação das empresas no mercado e na sociedade. O intuito dos processos de inovação dirigida pelo design é geralmente a definição de novos cenários de atuação competitiva para empresas e outras organizações. Tais processos visam ao encontro de um ponto de vista inédito, alternativo ou futuro, sobre os contextos de atuação competitiva das empresas, e à geração de visões capazes de mostrar as possibilidades que se abririam se esse ponto de vista fosse aplicado. O objetivo final é identificar uma trajetória de inovação praticável, que permita o desenvolvimento coerente da organização.

Além disso, Vianna, Vianna, Adler, Lucena e Russo (2012, p.12 ) assinalam:

Com o passar do tempo, empresas passaram a perceber que já não bastava oferecer apenas superioridade tecnológica ou excelência em desempenho como vantagem mercadológica, pois tanto as companhias de pequeno quanto as de grande porte espalhadas pelo mundo já haviam começado a se adequar a esta realidade. No cenário de competição global que em breve se tornaria vigente, inovar seria uma tarefa árdua e muitas vezes frustrante. A dificuldade de obter diferenciação de mercado sobre a concorrência seria cada vez maior. Novos caminhos precisavam ser traçados, não apenas para garantir o êxito das empresas, mas, principalmente, sua sobrevivência.

Ainda, Vianna et al. (2012, p.13) complementam ao mencionar que:

foi buscando novos caminhos para a inovação que se criou o que hoje é conhecido como Design Thinking: uma abordagem focada no ser humano que vê na multidisciplinaridade, colaboração e tangibilização de pensamentos e processos, caminhos que levam a soluções inovadoras para negócios.

Segundo Brown (2009), o que distingue uma organização que aplica o Design Thinking é o número de protótipos desenvolvidos a partir do ciclo de etapas disponíveis, que gera a possibilidade de comparação de outros projetos com projetos atuais, proporcionando dessa forma a melhoria e a continuidade do projeto.

Assim, revela-se a necessidade de frequentemente inovar para não perder espaço no mercado, conforme evidencia a afirmação do CEO da Apple, Tim Cook:

Sou velho o suficiente para me lembrar de quando a Nokia tinha margens de lucro de $25 \%$ e não tinha como ela perder a liderança. Acho que isso é um lembrete a todos do mundo dos negócios de que você precisa continuar inovando, e que não inovar é morrer (Bloomberg, 2013).

Joseph Schumpeter (1942, citado por Pinheiro, Alt \& Pontes, 2012), baseado na teoria do ciclo econômico, refere que a economia somente sai 
de seu ponto de equilíbrio e passa para o processo de expansão com o surgimento de inovações. Essas mudanças na economia por muitas vezes foram o fator crucial para a perda de valor e até mesmo para o fechamento de algumas empresas, que por sua vez fomentam a substituição de tecnologias e processos por outros mais adaptados à realidade do mercado e das pessoas.

Para manter a economia crescendo, é fundamental inovar, pois a inovação acontece quando há uma mudança de valores e a reorganização destes abre espaço para novas formas de prosperidade.

Dessa forma, a vida das pessoas e seu trabalho são afetados no momento em que a ideias se transformam em valor por meio da inovação. Por conseguinte, "a inovação é fruto da criatividade colocada em prática com o intuito de gerar resultados positivos para o negócio e criar impacto positivo para as pessoas" (Pinheiro et al., 2012, p. 24).

A criação de ideias inovadoras é um processo complexo. Ultimamente, os principais ativos das organizações são intangíveis, predominando um grande foco no conhecimento. Por isso, inovar, transformar insights em oportunidades para gerar novos negócios pode ser considerado ponto estratégico para garantir a sobrevivência das corporações nos dias de hoje e "o Design Thinking pode identificar um aspecto de comportamento humano, e depois convertê-lo em benefícios para o consumidor, além de adicionar valor ao negócio" (Brown, 2010, p.36).

\subsection{O QUE É DESIGN THINKING}

Conforme aponta Brown (2010), o Design Thinking (pensar como um designer) pode modificar a maneira de desenvolver produtos, serviços e processos. A abordagem Design Thinking emprega a sensibilidade e os métodos do designer para atender às necessidades das pessoas com o que é tecnologicamente viável e cria uma estratégia de negócios duradoura, proporcionando a conversão desta necessidade em valor para o cliente e oportunidade de mercado. 
O termo Design Thinking foi mencionado pela primeira vez em 1992 em um artigo do renomado professor da Universidade de Carnegie Mellon Richard Buchanan denominado "Wicked problems in Design Thinking". Nesse artigo, o autor apresenta o potencial de abordagem do design em quatro frentes, permitindo que seja expandido a outras disciplinas: design na comunicação visual, design de produtos, design aplicado a serviços e uma abordagem na construção de melhores ambientes para as pessoas viverem e trabalharem (Pinheiro et al., 2012, p. 48).

Há mais de 30 anos, o uso do design tem sido estudado em arquitetura, ciências e artes para desenvolver soluções, porém, as aplicações do design também estão se expandido e sendo aplicadas ao ramo dos negócios. A origem dessa nova aplicação está associada à empresa norte-americana de consultoria IDEO, que desenvolve inovações com base no pensamento de um designer, tendo surgido daí o conceito Design Thinking.

Atualmente o termo design é associado à qualidade e/ou à aparência estética de produtos, entretanto a intenção do termo faz referência a promover o bem-estar na vida das pessoas. Esse termo tem chamado muito a atenção de gestores, proporcionando novos caminhos para a inovação empresarial com base nas possibilidades que o design permite abranger:

O designer distingue como um problema tudo aquilo que prejudica ou impede a experiência (emocional, cognitiva, estética) e o bem-estar na vida das pessoas (considerando todos os aspectos da vida, como trabalho, lazer, relacionamentos, cultura, etc.). Isso faz com que sua principal tarefa seja identificar problemas e gerar soluções (Vianna et al., 2012, p. 8).

Dessa forma, o designer busca entender problemas que comprometem o bem-estar das pessoas, utilizando a empatia, ou seja, colocando-se no lugar do outro e procurando entender melhor o contexto em que essa pessoa está inserida, bem como identificando as causas e as consequências das dificuldades para ser mais assertivo na busca por soluções. Compreender o método que o designer emprega para a elaboração de soluções pode originar insights fundamentais para a área dos negócios.

O equilíbrio entre o pensamento analítico e o intuitivo é promovido durante a aplicação da metodologia Design Thinking, que, segundo Martin 
(2009), permite aumentar a eficiência e a competitividade gerando inovação nos processos, produtos e serviços das organizações. Possibilita, ainda, que as empresas transcendam de um ambiente complexo para um simples, através do "funil" do conhecimento em que são aplicadas técnicas para filtragem dos melhores insights.

Ainda, Martin (2009) lembra que, usando-se a lógica abdutiva, é possível aplicar o Design Thinking, conceito desenvolvido originalmente por James Peirce, o que permite a exploração de possibilidades em direção ao futuro, em paralelo com oportunidades analisadas sob a ótica do passado.

Brown (2009) refere que o Design Thinking busca o desenvolvimento de soluções impecáveis esteticamente e com novas funcionalidades, criando novas experiências, valores e, principalmente, significado para os consumidores. Sendo assim, baseia-se na capacidade de ser intuitivo, reconhecer padrões, desenvolver ideias que tenham um significado emocional além do funcional.

Ao contrário da abordagem tradicional analítica que incentiva que devemos nos mover na direção mais razoável para solucionarmos problemas, o pensamento do Design propõe que devemos nos mexer primeiro para gerar opções que nos levarão a encontrar um caminho e não escolher primeiro um caminho e então gerar opções (Pinheiro et al., 2012, p. 43).

Ainda conforme Brown (2010), o Design Thinking é compreendido como um sistema de sobreposição de espaços diferentes de uma sequência ordenada de etapas. Segundo o autor, esse sistema é dividido em "três etapas de inovação": inspiração, quando insights de todos os tipos são coletados; ideação, etapa na qual os insights são traduzidos em ideias; e implementação, em que as melhores ideias são desenvolvidas em plano de ação concreto.

Contrary to popular opinion, you don't need weird shoes or a black turtleneck to be a design thinker. Nor are design thinkers necessarily created only by design schools, even though most professionals have had some kind of design training. My experience is that many people outside professional design have a natural aptitude for design thinking, which the right development and experiences can unlock (Brown, 2008, p. 87).

Em tradução livre do texto acima, de acordo com Brown (2010), podemos observar que não necessariamente um design thinker é formado em uma escola de design ou tem que ser considerado um profissional em 
design para ter capacidade de desenvolver inovações, pois as pessoas possuem uma aptidão natural resguardada, necessitando apenas desbloquear essa habilidade de criação através da prática e da efetuação de experiências.

Contudo, ressalta-se que o princípio de empatia, de pensamento focado nas pessoas, facilita a criação de soluções pertinentes desejáveis e que atendam às necessidades, mas nem todos estão preparados para aplicar essas percepções e criar soluções inovadoras. por isso, justapor uma visão integrada a uma visão focada em processos analíticos a fim de identificar todos os aspectos relevantes em um problema buscando desenvolver novas soluções é considerada outra característica que um design thinker deve possuir.

Além disso, partilhar de otimismo é fundamental para assumir que não importa o grau de dificuldade de um problema, mas, sim, qual é a possível solução mais propícia a melhorias do que opções vigentes. Todavia, inovações expressivas não são criadas a partir de adaptações incrementais, uma vez que a experimentação auxilia na elaboração de questionamentos para entender o problema e explorar restrições criativas, resultando em novas soluções significativas.

Outra particularidade observada no perfil de um design thinker parte do princípio de que o criador solitário é um mito, uma vez que está cada vez mais difícil criar soluções genuínas que reflitam a realidade e o entusiasmo dos beneficiados por essa solução. Dessa forma, a colaboração de outras áreas, além da principal, faz toda a diferença no processo de criação de soluções inovadoras.

Assim, características como empatia, pensamento integrado, otimismo, experimentação e colaboração, observadas nos design thinkers, são vistas por Brown (2010) como determinantes.

Contudo, essa metodologia coloca ferramentas importantes em contextos estratégicos diversos nas mãos de pessoas que não necessariamente são designers por formação, mas que precisam pensar e aplicá-las a uma variedade ampla de problemas para criar soluções inovadoras e sustentáveis para a empresa (Brown, 2010). 


\subsection{ETAPAS DO DESIGN THINKING}

Brown (2009) menciona que os projetos de design apresentam algumas restrições, que afetam a disposição e a aceitação que compõem as etapas do Design Thinking. Algumas restrições descritas estão ligadas a três critérios: praticabilidade (o que em um futuro próximo é possível ser funcional), viabilidade (o que se encaixa no modelo de negócios da organização) e desejabilidade (o que desperta o interesse e faz sentido para as pessoas), tornando-se ideal buscar um equilíbrio entre as restrições.

Dessa forma, busca-se através da empatia idealizar a solução partindo do princípio de múltiplas perspectivas concebidas pela visão de cada envolvido no projeto. Ao abordarem as pessoas como principal foco do projeto, os designers ou idealizadores passam a imaginar soluções que são prioritárias, desejáveis e que contemplem as necessidades apontadas ou ramificadas.

\subsubsection{Inspiração}

A primeira fase do processo de Design Thinking é chamada inspiração ou imersão. Nesse momento a equipe de projeto aproxima-se do contexto do problema, tanto do ponto de vista da empresa quanto do usuário final o cliente do cliente. (Vianna et al., 2012, p. 21).

Nesta etapa são identificados e coletados insights que podem ser considerados oportunidades geradas a partir de uma observação pessoal, a partir do momento em que se coloca no lugar de outra pessoa, ou seja, quando se assume uma postura empática. Esse processo auxilia a entender o negócio diante dos olhos do consumidor estabelecendo uma proposta de valor:

A Imersão Preliminar, portanto, tem como finalidade definir o escopo do projeto e suas fronteiras, além de identificar os perfis de usuários e outros atores-chave que deverão ser abordados. Nesta fase, é possível também levantar as áreas de interesse a serem exploradas de forma a fornecer insumos para a elaboração dos temas que serão investigados na Imersão em Profundidade (Vianna et al., 2012, p. 22). 
Normalmente a equipe desconhece o tema, sendo a imersão preliminar responsável por auxiliar no conhecimento do problema, visando aproximar os indivíduos ligados ao projeto, ao problema a ser trabalhado, o que proporciona novas perspectivas através do entendimento inicial dos usuários, da identificação dos perfis dos principais envolvidos, entre outros.

Para tanto, depois de compreendido o problema, a etapa seguinte consiste em conhecer os usuários e os perfis dos principais envolvidos. Nesta fase, deve-se buscar aprofundar o tema por meio de uma imersão em profundidade, que visa identificar comportamentos e mapear padrões e necessidades:

Essa pesquisa consiste em um mergulho a fundo no contexto de vida dos atores e do assunto trabalhado. Geralmente, procura-se focar no ser humano com o objetivo de levantar informações de quatro tipos: O que as pessoas falam? Como agem? O que pensam? Como se sentem? (Vianna et al., 2012, p. 36).

Assim, as etapas de imersão preliminar e imersão em profundidade são determinantes no processo de análise e síntese das informações, uma vez que os dados coletadas por meio dos insights gerados na etapa de inspiração favorecem a maior compreensão do problema.

\subsubsection{Ideação}

$\mathrm{Na}$ ideação, todas as oportunidades observadas na etapa de inspiração são trabalhadas através da síntese de informações, que tem como objetivo refinar as oportunidades e gerar ideias para o projeto. A partir da descoberta das necessidades, identificadas na primeira etapa, busca-se explorar possibilidades para melhorar o conceito da ideia por meio de técnicas de cocriação, preferencialmente trabalhadas em conjunto com os usuários:

Brainstorming é uma técnica para estimular a geração de um grande número de ideias em um curto espaço de tempo. Geralmente realizado em grupo, é um processo criativo conduzido por um moderador, responsável por deixar os participantes à vontade e estimular a criatividade sem deixar que o grupo perca o foco (Vianna et al., 2012, p. 101).

Outra técnica empregada na validação das ideias geradas consiste na ferramenta de análise estratégica matriz de posicionamento, que tem como objetivo amparar o processo de decisão por meio do entendimento mais 
eficiente dos benefícios e desafios de cada solução. Dessa forma, as ideias com potencial mais elevado são selecionadas para que seja desenvolvido um protótipo dessa solução.

O design thinker, portanto, dá forma a um pensamento que contribui para o processo do pensamento divergente, criando alternativas distintas. Porém, Brown (2010) menciona que somente acumular alternativas não passa de um exercício, sendo necessário que, na etapa de ideação, sejam selecionadas as melhores ideias e convertidas em algo tangível, passando da geração para a resolução de ideias, até a etapa de prototipagem.

\subsubsection{Implementação}

No Design Thinking trabalha-se intensamente a criação de oportunidades, ou melhor, hipóteses, que são resultado de sessões de criatividade que criam e reciclam o conhecimento gerado pela prototipagem. Os protótipos desenvolvidos têm como objetivo ir além dos pressupostos que bloqueiam soluções eficazes e realmente inovadoras (Bonini \& Endo, 2010, p. 4).

Criação e desenvolvimento de protótipos do projeto fazem parte da etapa de implementação, na qual, a partir das ideias geradas na ideação, são colocadas em prática ações para tornar tangível e dar forma à ideia. A maior parte dos projetos de DT fracassa no momento da implementação. Eles podem não ser viáveis do ponto de vista tecnológico nem financeiramente rentáveis ou ainda porque a empresa não consegue leválos ao mercado com sucesso (Nakagawa, 2014, p. 3).

Segundo Bonini e Endo (2010), ao contrário de modelos tradicionais em que os protótipos visam tornar mínimos os riscos e a classificação do potencial de lucratividade, esses protótipos abordados auxiliam a adaptar e melhorar as ideias de maneira ágil e sem necessidade de grandes investimentos, buscando aprendizado rápido sobre os pontos fortes e fracos da ideia, além da identificação de novos rumos e redução das chances de fracasso:

A experimentação é, para nós, parte inseparável do processo de construção do raciocínio. Ela nos permite externar ideias de maneira que possam ser absorvidas e complementadas por outras pessoas enquanto são concebidas. Assim, construímos e pensamos juntos. A capacidade de as pessoas apresentarem o que pensam de forma rica e envolvente é um catalisador fundamental do processo de inovação. E os protótipos são os meios que permitem que isso aconteça de maneira tangível e com menor 
perda de significado possível entre o que foi imaginado e o que está sendo comunicado (Pinheiro et al., 2012, p. 115).

Dessa forma, os protótipos, por meio da implementação e da experimentação do Design Thinking, propiciam falhar cedo e aprender lições preciosas com os erros, consentindo aprimoramento da proposta e melhoria contínua da solução até o lançamento final.

\begin{abstract}
Um modelo mais experimentador não é só mais inteligente e menos arriscado. Ele representa a única maneira de um negócio conseguir se adaptar com relevância na velocidade que o mercado varia nos dias de hoje. De um lado algumas empresas ainda relutam em encarar a experimentação constante como parte de sua estratégia de desenvolvimento. Do outro, muitos concorrentes dessas empresas já abraçaram essa cultura de valor que tem como sua principal resultante a injeção constante de inovações de alto impacto no mercado (Pinheiro et al., 2012, p. 117).
\end{abstract}

Ressalta-se que os protótipos têm como objetivo testar e validar hipóteses, mas, para que um protótipo funcione, deve ser considerada a possibilidade de falha. Diferentemente do que muitos acreditam, falhar não significa perder mas, sim, uma forma de corrigir erros o mais cedo possível e adequar o protótipo, o que em muitos casos é o fator crucial que leva a solução ao sucesso.

\title{
3. METODOLOGIA UTILIZADA
}

Para validação do Design Thinking como abordagem para gerar ideias e negócios inovadores, a metodologia foi utilizada na disciplina de Criatividade e Inovação de um curso de bacharelado de Sistemas de Informação, com 24 estudantes com idades entre 22 e 31 anos. A faculdade em que esse curso está inserido tem dez cursos de graduação, dois mestrados e 36 cursos de pós-graduação lato sensu, com um total de cinco mil estudantes matriculados.

Apesar de Criatividade e Inovação ser uma disciplina curricular de Sistemas de Informação, dos alunos, dez eram estudantes de Administração e 14 de Sistemas de Informação, visto que a disciplina é oferecida com cursos mistos. Desse total, 13 estudantes eram mulheres e 11 homens, e os grupos foram construídos de forma aleatória, sem a chance de escolha dos estudantes. 
Foram utilizados quatro encontros da disciplina com o tema da pesquisa, como é mostrado na Figura 1, com a finalidade de: a) apresentar o DT; b) imergir os estudantes para análise de necessidades ainda não atendidas nas dependências da faculdade; c) projetar uma solução para a necessidade; d) prototipar e validar com os usuários reais.

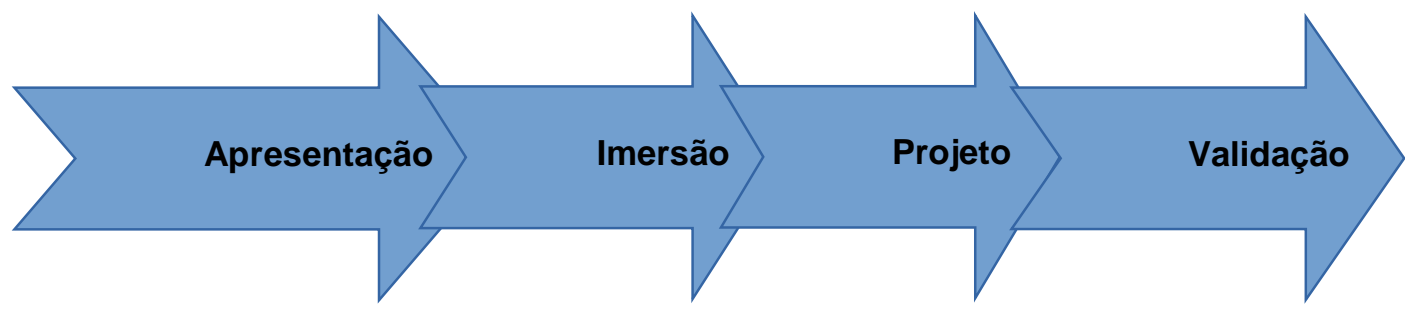

Figura 1: Etapas do Design Thinking utilizadas na pesquisa

a) Apresentação Design Thinking: nesse primeiro encontro, foi apresentada a bibliografia básica de Design Thinking, citada no referencial teórico deste trabalho. Após a explanação, todos participaram de um storytelling para mobilizar os membros a pensarem de forma criativa. Ao final do encontro, foram formados quatro grupos de seis membros desafiados a caminhar no campus à procura de uma necessidade dos estudantes - produto ou serviço inovador - ainda não atendida. Eles deveriam retornar com o tema escolhido no encontro seguinte.

b) Imersão para Análise de Necessidades: nesse segundo encontro, os estudantes deveriam trazer escolhida e debatida a necessidade real dos estudantes do campus ainda não atendida. 0 grupo A trouxe ideias ligadas a atendimento do Xerox; o grupo B, melhorias na biblioteca; e os grupos C e D pensaram em melhorias na cantina central. Nesse encontro, eles deveriam imergir in loco no fornecimento dos serviços, identificando gargalos e buscando insights para melhoria ou criação de novos serviços, anotando tudo em documentos de registro de observação, que foram apresentados e debatidos posteriormente, gerando análises coletivas do grande grupo. Após isso, foi gerado um questionário com seis perguntas fechadas e duas abertas, sobre o estado atual e sugestões de 
melhorias, buscando identificar gargalos ou oportunidades. Cada questionário foi respondido durante a semana por 30 indivíduos-alvo da pesquisa, e fez-se uma compilação para ser apresentada no encontro seguinte.

c) Projeto da Solução: nesse terceiro encontro, os estudantes apresentaram a compilação do questionário e, com base nele, projetaram a melhoria ou novo produto/serviço baseados nas necessidades coletadas e análises individuais de cada membro, do pequeno grupo de seis pessoas e do grande grupo de 24 . 0 Projeto foi desenhado usando-se o Business Model Canvas, e ao final os projetos foram validados pelo grande grupo, sob o aspecto de relevância da solução e viabilidade técnica e econômica.

d) Prototipação e Validação da Solução: nesse quarto encontro, os estudantes usaram o projeto desenvolvido no modelo Canvas, e com ele criaram cenários de uso ou melhoria do serviço. Nesse momento foi feita a prototipação, em que eles encenaram como o produto ou serviço novo seria entregue aos estudantes, momento em que o grande grupo fez paradas, debate e feedback. Após as melhorias ou gargalos registrados, cada grupo atualizou seu projeto e validou in loco com os verdadeiros clientes dos serviços, nos locais onde os produtos/serviços eram utilizados, gerando a última validação do processo. Ao final, os projetos foram apresentados em sua versão final e abriu-se debate para processamento das atividades e do experimento da disciplina.

\section{DISCUSSÃO E CONCLUSÕES}

A mobilização gerada pela aplicação do Design Thinking nessa disciplina pode conectar o conteúdo didático e acadêmico com a realidade empresarial, visto que os projetos aqui apresentados estão em processo de pré-incubação da incubadora tecnológica da instituição, podendo participar de banca de incubação. 
Como resultados qualitativos, os demais cursos de graduação da faculdade mostraram-se interessados em executar as oficinas, tornando-se cada vez mais real a possibilidade de formar uma rede de pesquisa em Empreendedorismo e Inovação. Também foi possível identificar um maior engajamento dos estudantes na disciplina, em que a ferramenta serviu de prática para os processos de ideação e prototipação que antes só eram mostrados na teoria.

Com um enfoque pragmático e funcional, o Design Thinking contempla todo o processo de inovação, desde a visualização de insight a partir da utilização da empatia, até a visualização de potenciais oportunidades que agreguem valor para o usuário. Além disso, envolve a filtragem e a geração de ideias baseadas nos insights e no desenvolvimento de ideias com protótipos.

Esta abordagem tem uma visão otimista, construtiva e experimental, focada na resolução de necessidades dos usuários com relação a produtos e serviços. Ainda, contribui, principalmente, com o modo como é abordado o problema, através de ferramentas que possibilitem agrupar as necessidades que nortearão o procedimento de criação de oportunidades desejáveis aos usuários, mercadologicamente viáveis e tecnicamente possíveis de serem desenvolvidas.

No debate final, os estudantes elucidaram que Ihes chamou a atenção o fato de que no Design Thinking, o usuário desempenha um papel fundamental no processo, e o thinker busca criar hipóteses e utilizar seu conhecimento para criar soluções eficazes. Compreenderam ainda que a rápida prototipagem e a transformação da ideia em algo mais tangível favorece um ambiente de aprendizagem e implementação, bem como oportuniza a seleção de soluções que causem maior impacto e que atendam às necessidades esperadas.

Ainda, como resultados quantitativos, dos 24 estudantes, dois são proprietários de empresa e 14 trabalham em empresas de TI ou setores de Gestão, e propuseram levar a metodologia para suas empresas, como ferramenta de inovação. Devido ao fato de o experimento ser recente, ainda não foi possível avaliar o impacto nas empresas ou nas carreiras dos estudantes. 
Como trabalhos futuros, para uma segunda edição em 2015-1, o tempo será ampliado, incluindo uma etapa teórica para construção da pesquisa com os usuários, a pesquisa desk e o questionário, e serão oferecidas metodologias mais apuradas de análise e compilação de dados, para diminuir a dedução pessoal e aumentar a assertividade dos projetos. 


\section{REFERÊNCIAS}

Bloomberg, Business Week Technology. 2013 (September, 20).Apple Chiefs Discuss Strategy, Market Share-and the New iPhones. Recuperado em 19 de julho, 2015, de http://www.businessweek.com/printer/articles/153204-apple-chiefsdiscuss-strategy-market-share-and-the-new-iphones

Bonini, L. A., \& Endo, G. de B. 2010. Design Thinking: uma nova abordagem para inovação. Recuperado em 23 de maio, 2015, de 2010. http://biblioteca.terraforum.com.br/BibliotecaArtigo/artigodesignthinking.pdf

Boston Consulting Group. 2006. Innovation 2006. Recuperado em 03 de julho, 2015, de http://www.bcg.com/documents/file14826.pdf

Brown, T. 2009. Change by design: how design thinking transforms organizations and inspires innovation. New York: HarperCollins. Recuperado em 03 de julho, 2015, de http://www.ecologyofdesigninhumansystems.com/wpcontent/uploads/2012/09/Change-By-Design-Tim-Brown.pdf

Brown, T. 2010. Design thinking: uma metodologia poderosa para decretar o fim das velhas ideias. Rio de Janeiro: Elsevier.

Brown, T. 2008 - Design Thinking. Harvard Business Review, June 2008 Issue, p.84-87.

Franzato, C. 2011. O processo de inovação dirigida pelo design: um modelo teórico. Redige, 2(1), 50-62. Recuperado em 20 de julho, 2015, de http://www.cetiqt.senai.br/ead/redige/index.php/redige/article/download /72/138\&ei=gc8xuu6jioa29gtq8yhgcw\&usg=afqjcngdv6s4jou5ld2tranza myi8rfwow\&bvm=bv.52109249,d.ewu

Martin, R. L. 2009. The design of business: why Design Thinking is the next competitive advantage. Boston: Harvard Business Press.

Nakagawa, M. 2014. Ferramenta: Design Thinking para empreendedores. Recuperado em 23 de maio, 2015, de http://cmsempreenda.s3.amazonaws.com/empreenda/files_static/arquivos/2014/0 4/07/Design_Thinking_.pdf

Pinheiro, T., Alt, L., \& Pontes, F. 2012. Design Thinking Brasil: empatia, colaboração, e experimentação para pessoas, negócios e sociedade. São Paulo: Elsevier.

Vianna, M., Vianna, Y., Adler, I. K., Lucena, B., \& Russo, B. 2012. Design thinking: inovação em negócios. Rio de Janeiro: MJV Press. Recuperado em 03 de julho, 2015, de http://www.sebraedesign.com/wpcontent/uploads/2013/05/Design-Thinking-Inova\%C3\%A7\%C3\%A3oem-Neg\%C3\%B3cios.pdf 